\title{
Research on the Construction of Guiding Ideological System of School Physical Education in the New Era \\ Yang Li
}

School of Physical Education, Tonghua Normal University, Tonghua, 134002, China

\begin{abstract}
In the new era, the four school physical education guiding thoughts coexist, namely quality-oriented education, student-based education, health first and lifelong sports. However, the four different guiding thoughts emphasize different points. The school physical education reform takes quality-oriented education as the center, lifelong sports as the development objective, student-based education as the value guidance and health first as the guideline. However, the four school physical education guiding thoughts fail to promote the improvement to physical condition of students. In this paper, the author thought that the physical education thought was beneficial for improving physical fitness of Chinese students. At the same time, the author also proposed to construct the guiding ideological system of Chinese school physical education.
\end{abstract}

Key words: school physical education, guiding thought of physical education, system education, ideological system

At present, the issue of declining physique of Chinese students becomes more and more serious. There are many reasons for this phenomenon, including nutrition, heredity, degeneration and optimization. No matter for whichever reason, the declining physique of students will exert influence on the future of both individual students and our nation. As an important course of guiding students for physical exercise, school physical education is also responsible for the declining physique of students to some extent. Therefore, we must begin with the "source" of guiding thought of school physical education, research the current situation of school guiding thought and establish a school physical education guiding ideological system which can improve the physical fitness of Chinese students.

\section{Emphasis on the Current School Physical Education Guiding Thought in China}

1. School physical education under the background of quality-oriented education lays particular emphasis on "quality" instead of "quality”.

In 2006, the State Council issued the outline of "the $11^{\text {th }}$ Five-Year Plan", and clearly pointed out that educational business must adhere to the subject of "quality-oriented education" in the period of "the $11^{\text {th }}$ Five-Year Plan". In 2010, China issued medium and long term educational development outlines and defined the strategic theme of educational reform development as 
comprehensive implementation of quality-oriented education ${ }^{[1]}$. Under the overall background of quality-oriented education, school physical education will inevitably implement the guiding thought of quality-oriented education, take integrated development of students as the objective, pay attention to the improvement to overall quality of students and lay emphasis on practical ability and innovation ability of students. Just because of this, the emphasis of quality-oriented education is "quality" instead of "physique". School physical education, with the thought of quality-oriented education as guidance, also results in ignorance of physical training of students to some extent.

\section{The guiding thought of "student-based" school physical education lays particular emphasis on "people" instead of "body".}

In the new era, the "student-based" guiding thought requires to take the development of students as the basis, comprehensive and accord development as the quality requirement, mutual development of all students as the quantitative requirement, positive development of students as the approach, to embody characteristics of the times with personality development of students and to take sustainable development of students as the final objective ${ }^{\text {[2] }}$. In one sense, traditionally distorted value orientation of education is distorted under the "student-based" thought. Students are taken as subjects of education. It is of great significance for the improvement to educational quality. However, the "student-based" thought lays particular emphasis on overall education, which is not especially designed for a certain subject. Therefore, it fails to effectively solve specific issues of a certain subject. As a result, school physical education takes "student-based" as the guiding thought of sports and lays emphasis on “people” instead of "physique” of students.

\section{The "lifelong sports" guiding thought of school physical education attaches importance to "interest" instead of "physique".}

In the new era, school physical education curriculum reform also gives expression to the thought of lifelong sports. Schools combined short and long term benefits and integrated social physical education, school physical education and family physical education together, influencing the development of school physical education in China. Generally speaking, most new physical education guiding thoughts were resulted from reflections on disadvantages of physical education. For instance, quality-oriented education appeared against exam-oriented education. Student-based education appeared against subject orientation and social orientation. However, the thought of lifelong sport also includes other contents. It was sourced from the guiding thoughts of school physical education with the purpose of changing the condition of students leaving physical education after leaving school ${ }^{[3]}$. Therefore, lifelong sport, as the 
guiding thought of school physical education, is of forward looking. At the same time, it is also served as the requirement of school physical education development and the ideal objective pursued by school physical education. Therefore, it is also of guidance for school physical education. However, school physical education takes lifelong sport as the guiding thought. It certainly will enhance long-term interests and take physical education habits and interests of students as emphasis of cultivation. However, "physique" of students will be naturally neglected.

\section{The "health first" guiding thought of school physical education attaches importance to overall "health" instead of "physique".}

In 2001, China issued standards for physical education curriculum and definitely pointed out that school physical education should take "health first" as the guiding thought. At the same time, specific contents of three-dimensional health were planned. The first three educational thoughts were mostly proposed by the academic circle. However, the guiding thought of "health first" is firstly proposed by the governmental education department. Then, the thought received attention from the academic circle. Although there are many factors influencing health of students, physical education plays an irreplaceable role in improving mentality, physiology and social adaptability of students ${ }^{[4]}$. In the new era, the guiding thought of "health first" lays particular emphasis on "three-dimensional outlook of health". Much attention is paid to overall health, especially for psychological health and social adaptability of students. Therefore, school physical education's taking "health first" as the guiding thought certainly will emphasize psychological health of students and overlook their development of "physique".

\section{Significance of Physique Education Guiding Thought for Development of School Physical Education}

\section{Physique educational thought takes strengthening physique as the core.}

Different from aesthetic education, intellectual education and moral education, physical education stresses training for "body". The realization of physical education function is also based on exercises of "body". Through exercises of "body", however, the most obvious effect is strengthening of physique. Compared with education of other subjects, the essential attribute of physical education is to enhance physique. Therefore, this also indicates that the practice taking strengthening physique as the objective can not be expanded into all school educations. It is only applicable to the development of physical education works. This also guarantees that physical education plays an important role in school education. The essence of school physical education is to strengthen physique of students. However, physique education grasped the foundation of school physical education and solved the issue of physical development of 
students. Therefore, it is of effective guidance for the improvement to physique of students.

2. It is amenable to take physique education as the guiding thought of school physical education.

The guiding thought of physique education adheres to the principle of physical education as education of strengthening physique. It is provided with a very perfect theoretical system. According to the law of overload, it takes the motion load value threshold as the principle of training. Through exercise plans, various training methods are used to enhance physique of students. In the new era, numerous Chinese scholars made considerable explorations for and researches on guiding thoughts of physique education. Xu Yingchao, a famous Chinese gymnast, made an experiment on physique education in many elementary and secondary schools. Some scholars made a limit load experiment on students in Junior Two. A school in Fujian Province divided physical education curriculum into two parts: half of time for PE classes is for physique training of students. These experiments and practices obtained favorable results. Moreover, many scholars also made a research on guiding thoughts of physique education, enriching practical experiences in guiding thoughts of physique education. In a long period of time, Chinese school physical education took physique education as the guiding thought. Physique of students was obviously improved. In early years of the new nation, Chinese school physical education took “build up people’s health” as the guiding thought and required students to positively participate into all kinds of physical exercises, so as to strengthen physique and improve physical quality. On the Yangzhou Meeting in 1979, it was definitely pointed out that the strengthening of students' physique was the fundamental method used to assess teaching performance of primary school physical education. On Xi'an Meeting in 1983, it was also definitely pointed out that the strengthening of students' physique was the essential objective of school physical education. On this basis, the guiding thought of physique education was established. After that, school physical education classes and extracurricular activities got development. Students' consciousness of physical training was strengthened. Moreover, their interests in physical exercises were obviously improved, and their physique was remarkably improved as well.

\section{Upon development, the guiding thought of physique education was gradually perfected.}

Any kind of guiding thought of school physical education was generated under certain historical background. Therefore, it will also limited by history. It is also the same for guiding thought of physical education. In the process of practice, much attention was paid to exercise intensity. The teaching method was too single. Students felt tired and lost interest of learning. Many people treated the guiding thought of physique education as the realization of physical 
enhancement of students by overlooking “psychology”, “culture” and other targets. At the same time, due to impact from other guiding thoughts of physique education, people gradually forgot the guiding thought of physique education. However, the guiding thought of physique education never stayed still due to this reason. On the contrary, it kept up with the step of times and changed constantly. Under the precondition of admitting other advanced guiding thoughts, the guiding thought of physique education absorbed the essence of all kinds of guiding thoughts with tolerant attitude. Firstly, the guiding thought of physique education is compatible with the guiding thought of "health first". Physical health is closely correlated with psychological health and social adaptability. However, emphasis on physique doesn’t overlook psychological health and social adaptability of students. Chinese scholars thought that brain was a key part in body composition. Physical training and physique strengthening includes brain training. Physique strengthening is served as the material precondition for guarantee of health. However, health is also served as the external expression of physique. Essentially, therefore, the two items come down in one continuous line. Secondly, the guiding thought of physique education also emphasizes lifelong sports. The essential objective of physical education is to strengthen physique, which includes strengthening body education of family members, school students and social members. Thirdly, the guiding thought of physique education also stresses "people orientation”, taking human's body development as the scientific view of sports. Under the background of quality-oriented education, numerous Chinese scholars proposed that the guiding thought of physique education should face the content system of quality-oriented education in the new century and explore for new contents. Therefore, we can see that the guiding thought of physique education in the new era have already absorbed the essence of other guiding thoughts and made up its deficiencies on the basis of attention to physique improvement to students.

\section{Construction of China's School Physical Education Guiding Ideological System in the} New Era the

\section{Construct a diversified guiding ideological system of school physical education}

According to the analysis on various kinds of guiding thoughts of school physical education in the new era in above paragraphs, we can see that all kinds of thoughts lay particular emphasis on different contents. Moreover, they can solve certain issues. At the same time, it is also very difficult for them to estimate some places. Therefore, each thought has both advantages and disadvantages. For instance, it will not be caught into the blame of "biological view of physical education” if physique education is taken as the guiding thought of school physical education. If quality-oriented education, people oriented and others are taken as the guiding thought, it 
certainly will be unable to realize the essential objective of physical education or meet the needs of strengthening physique of students. Viewed from conditions of Chinese school physical education in the new era, therefore, it is irreplaceable for different guiding thoughts. They are in a state of coexistence. We must construct diversified guiding thoughts, absorb the essence of all kinds of guiding thoughts and realize complementary advantages of various kinds of thoughts ${ }^{[5]}$. Additionally, the construction of diversified guiding thoughts of school physical education is also decided by complexity of school physical education and essential features of various kinds of guiding thoughts.

\section{Construct a hierarchical guiding ideological system of school physical education}

Various kinds of guiding thoughts exist under an ordered way. It is of guidance for the development of school physical education at different levels. It was definitely specified in the Outline: at present, the development of Chinese educational reform takes "people-oriented" and “quality-oriented education” as two themes. The two kinds of thoughts specified the approach and the objective of education. In a macroscopic sense, it is of guidance for the overall situation of school education, the school physical education certainly will also take the two thoughts as the guidance. The guiding though of physique education can highlight the essence of physical education. It is of guidance for school physical education together with the guiding thoughts of lifelong sports and health first from the disciplinary perspective. According to the longitudinal analysis, macroscopic guiding thought is the governor. From the disciplinary perspective, the implementation of guiding thought should also take macroscopic guiding thought as the precondition ${ }^{[6]}$. From a horizontal perspective, complementary relations between various thoughts lay particular emphasis on different contents in defined levels. They all play an indispensable role in the development of school physical education.

\section{Construct an overall guiding ideological system of school physical education}

All kinds of guiding thoughts of school physical education lay particular emphasis on different contents. Therefore, the labor of division is also different. However, they penetrate into each other. They are integrated with each other. The development of school physical education requires each guiding through to participate into the process. No matter in any times, various kinds of guiding thoughts need to participate into the process jointly. In the face of different issues, different guiding thoughts will be selected. Therefore, the maximum overall resultant force can be generated to guarantee real development of school physical education by find out the key guiding thought of school physical education, giving play to advantages of each kind of guiding thought and realizing the effect of " $1+1>2$ ". 


\section{Conclusion}

To sum up, Chinese school physical education is confronted with the situation of many kinds of thoughts coexisting at the same time in the new era. Different guiding thoughts lay particular emphasis on different contents. With strengthening physique of students as the research point and according to features and advantages of different guiding thoughts, the author proposed to construct a diversified, hierarchical and overall guiding ideological system of school physical education. The long-term development of school physical education can be realized only by mastering features and functions of various thoughts, combining quality improvement with physical education skills of students, strengthening mutual development of physique of students and their health and realizing te combination of short-term and long-term interests of physical education under the guidance of this theoretical system.

\section{References:}

[1] Zhang Yizeng, Rational Reflection on the Construction of Guiding Thought of Chinese School Physical Education in the New Era [J], Journal of Sports Adult Education, 2006, (22): 69-71;

[2] Yang Shuzi and Yu Dongsheng, Quality-oriented Education: Great Achievements of China's Educational Thought in 30 Years of Reform and Opening Up [J], Journal of Higher Education Research, 2009, (06): 7-8;

[3] Li Yiping, Research on the Evolution Course of School Physical Education Thought in Modern Time of China [J], Journal of Fujian University of Technology, 2007, (02): 162-163;

[4] Wang Huazhuo, Discussion on the History of Physical Education Course in Modern Time of China [M], Beijing: Higher Education Press, 2004;

[5] Shao Xiaofeng and Liao Qifa, Interpretation of the Connotation of Student-oriented Educational Concept [J], Journal of The Chinese Society of Education, 2006, (03): 3-9;

[6] Li Jinlan, Physical Education in the New Era - Discussion on Cultivation of Individuality [J], Journal of Inner Mongolia Normal University (Educational Science), 2012, (03): 147-149. 